Shephend, C. J. (1956). J. gen. Microbiol. 15, 29-38

\title{
Pathways of Cysteine Synthesis in Aspergillus nidulans
}

\author{
BY C. J. SHEPHERD \\ Medical Research Council Unit for Chemical Microbiology, \\ School of Biochemistry, University of Cambridge
}

SUMMARY: Cysteine was formed from sulphate, sulphite and thiosulphate as inorganic sulphur sources, by acetone-dried powders of Aspergillus nidulans mycelium. Added pyridoxal was obligatory for cysteine synthesis with sulphate or sulphite, and this synthesis was further enhanced by the addition of sodium pyruvate and sodium glutamate. Concomitant accumulation of cysteine sulphinic acid and utilization of glutamic acid was demonstrated. With thiosulphate, considerable synthesis of cysteine occurred in the absence of supplements, but was much enhanced by the addition of serine. Cysteine sulphinic acid did not accumulate with thiosulphate as the inorganic sulphur source. Parathiotrophic mutants, produced by ultraviolet irradiation, were used in the further elucidation of the biosynthetic mechanisms involved. Two reaction sequences: sulphate $\rightarrow$ sulphite $\rightarrow$ cysteine sulphinic acid $\rightarrow$ cysteine; and thiosulphate $\rightarrow$ cysteine-S-sulphonic acid $\rightarrow$ cysteine probably take place in the mould.

Detailed information on sulphur metabolism in moulds was initiated by Steinberg's (1941) investigations into the utilization of various sulphurcontaining compounds by Aspergillus niger. He concluded that the reduction of such compounds is a normal preliminary process in inorganic sulphur utilization in this mould. Hockenhull (1948) obtained similar results for Penicillium notatum and described two parathiotrophic mutants of this mould. Parathiotrophic mutants of Ophiostoma multiannulatum had previously been produced by Fries (1945) and parathiotrophy had been observed in the Saprolegniaceae by Volkonsky (1933) and in Staphylococcus aureus by Fildes \& Richardson (1937). Hockenhull (1949) obtained a number of parathiotrophic mutants of Aspergillus nidulans and, from their growth behaviour on a number of compounds, postulated that sulphate was metabolized to cysteine with the intermediate formation of sulphite, sulphoxylate, thiosulphate and cysteine-S-sulphonic acid. Phinney (1948) and Phinney, Fling, Sheng \& Horowitz (1950) obtained evidence that in Neurospora crassa sulphite, thiosulphate, cysteic acid and cysteine sulphinic acid were intermediates between sulphate and cysteine. In Escherichia coli, the work of Lampen, Roepke \& Jones (1947) and of Cowie, Bolton \& Sands (1950) indicated that sulphite, thiosulphate and possibly sulphide, were intermediates between sulphate and cysteine.

Kearney \& Singer (1952, 1953) and Singer \& Kearney (1954) obtained evidence that in Proteus vulgaris oxidation of cysteine to sulphate occurs with the intermediate formation of cysteine sulphinic acid, $\beta$-sulphinyl pyruvic acid and sulphite, while Chapeville \& Fromageot (1954) have shown the formation of cysteine sulphinic acid from sulphite in rabbit kidney.

No experimental approach, using both metabolic studies and mutant studies simultaneously, has been made, and Aspergillus nidulans appears to offer 
reasonable material for this purpose, as the starvation method of Pontecorvo (1953) enables large numbers of parathiotrophic mutants to be produced with relative ease. It was hoped that information gained by the above approach would make it possible to reconcile and amplify previous studies with both A. nidulans and other organisms.

\section{METHODS}

Organisms. Aspergillus nidulans (Eidam) Wint. (Commonwealth Mycological Institute Culture Collection No. 16648) was used for the metabolic experiments and as the wild-type mould for the production of mutants.

For the isolation of mutants, approximately $20 \times 10^{6}$ conidia were suspended in $2 \mathrm{ml}$. 1:5000 Teepol solution, uv-irradiated in a rocked quartz dish until only $0.2 \%$ remained viable and plated out on minimal medium + cysteine. For the production of mutants by the starvation method of Pontecorvo (1953), a biotinless mutant derived from the wild type was used as the parent strain. The requirements of the parathiotrophic mutants produced were determined by the auxanographic method of Pontecorvo (1949).

Cultivation. The mould was grown in the following medium: $6.0 \mathrm{~g} . \mathrm{NaNO}_{3}$; $0.5 \mathrm{~g} . \mathrm{KCl} ; 0.5 \mathrm{~g}$. $\mathrm{MgSO}_{4} .7 \mathrm{H}_{2} \mathrm{O} ; 1.5 \mathrm{~g}$. $\mathrm{KH}_{2} \mathrm{PO}_{4} ; 20.0 \mathrm{~g}$. glucose; $95 \mu \mathrm{g}$. $\mathrm{Na}_{4} \mathrm{~B}_{4} \mathrm{O}_{7} .10 \mathrm{H}_{2} \mathrm{O} ; 393 \mu \mathrm{g}$. $\mathrm{CuSO}_{4} .5 \mathrm{H}_{2} \mathrm{O} ; 997 \mu \mathrm{g}$. FeSO ${ }_{4} .7 \mathrm{H}_{2} \mathrm{O} ; 158 \mu \mathrm{g}$. $\mathrm{MnSO}_{4} \cdot 4 \mathrm{H}_{2} \mathrm{O} ; 62 \mu \mathrm{g}$. $\left(\mathrm{NH}_{4}\right)_{2} \mathrm{MoO}_{4} ; 8 \cdot 8 \mathrm{mg}$. $\mathrm{ZnSO}_{4} \cdot 7 \mathrm{H}_{2} \mathrm{O}$ and $1000 \mathrm{ml}$. water. The $\mathrm{pH}$ value was adjusted to 6.8 before autoclaving at $15 \mathrm{lb} . / \mathrm{sq}$.in. for $15 \mathrm{~min}$. The medium was dispensed in $200 \mathrm{ml}$. amounts in 11 . flat-bottom flasks and aerated vigorously with a fast stream of air passed through a sintered-glass distributor, while being shaken with a frequency of 150 strokes/min. at an amplitude of $4 \mathrm{~cm}$.

Incubation was for $72 \mathrm{hr}$. at $20^{\circ}$ and resulted in a dense suspension of short pieces of vegative mycelium.

For growth studies, the mutants were grown on the above minimal medium supplemented with various sulphur compounds and biotin where necessary.

Enzyme preparations. The mycelium from the aerated shake culture was washed on a sintered-glass funnel with a large volume of distilled water, resuspended in $300 \mathrm{ml}$. distilled water and aerated for $5 \mathrm{hr}$. It was then filtered off and suspended in a large volume of ice-cold acetone. After standing overnight at $0^{\circ}$, the mycelium was again filtered on a sintered-glass funnel, washed with ice-cold acetone and ether and dried in vacuo over sulphuric acid. On a suggestion by $\mathrm{Dr}$ E. E. Snell, the mycelium was constantly aerated during all stages of manipulation until it was plunged into the ice-cold acetone. Lack of aeration during the filtration steps resulted in low and fluctuating activities in the acetone powders. Considerable endogenous production of cysteine was observed when mycelium was not starved in distilled water.

Reaction mixture. The total reaction mixture volume was $10 \mathrm{ml}$. consisting of $5 \mathrm{ml} .0 .067 \mathrm{M}$-phosphate buffer $(\mathrm{pH} \mathrm{7 \cdot 2}$ ) in which $100-200 \mathrm{mg}$. of acetone powder were suspended. Amino and keto acids and sulphur sources were added to a final concentration of $0.1 \mathrm{M}$, as sodium salts, and pyridoxal to a final concentration of $0 \cdot 01 \mathrm{M}$. 
Estimations. At the end of each experiment, the digest was centrifuged, the precipitate washed twice with $5 \mathrm{ml}$. distilled water, and the washings and supernatant fluid combined. The precipitate was suspended in $10 \mathrm{ml}$. distilled water and heated for $10 \mathrm{~min}$. in a boiling water bath. After cooling, solid material was removed by centrifugation. Cysteine and cystine were estimated directly on samples from the original supernatant fluid and on samples from the hot water extract by the method of Kassell \& Brand (1938). The results were expressed as $\mu \mathrm{g}$. cysteine, although the experimental manipulations led to the oxidation of varying proportions of the cysteine to cystine.

Chromatography of amino acids. For the production of satisfactory chromatograms it was found necessary to treat the extracts in the following manner in order to remove inorganic sulphur compounds. To a sample of the hot water extract $0 \cdot 1 \mathrm{~N}$ iodine solution was added until a faint yellow colour persisted; excess of saturated barium hydroxide solution was then added and carbon dioxide bubbled through the solution to remove excess barium hydroxide. The mixture was centrifuged and the supernatant fluid freeze-dried. After redissolving in 1-2 ml. water, 5-20 $\mu$ l. samples were chromatographed on Whatman no. 1 paper, using $n$-butanol + acetic acid + water $(4: 1: 5)$ or methanol + pyridine + water $(6: 2: 2)$ as solvents. The chromatograms were dipped in $0.2 \%(\mathrm{w} / \mathrm{v})$ ninhydrin in acetone and the colour developed by heating at $90^{\circ}$ for $15 \mathrm{~min}$. Semi-quantitative measurements of the amount of amino acid present were made by cutting out the coloured spots, eluting with $4 \mathrm{ml}$. of acetone + water (8:1) and measuring the colour in a Beckman Model DU spectrophotometer at a wavelength of $570 \mathrm{~m} \mu$.

Reagents. Analytical grade reagents were used wherever possible. Cysteine, cystine, methionine, taurine, isethionic acid and pyridoxal were obtained from L. Light and Co.; glutamic acid, aspartic acid and serine from Roche Products Ltd.; and sodium formaldehyde sulphoxylate from Brotherton and Co. Ltd. All amino acids were used in the form of their $\mathrm{L}$-isomers.

Cysteine sulphinic acid was prepared according to Levine (1986), cysteic acid according to Shinohara (1932), cystine disulphoxide according to Levine (1936), cysteine-S-sulphonic acid according to Clarke (1932), $\beta$-sulphonyl propionic acid according to Kharasch \& Brown (1940), $\alpha$-dihydroxy- $\beta$ dithiolpropionic acid according to Westerman \& Rose (1928) and oxalacetic acid according to Wohl \& Oesterlin (1901). Sodium pyruvate was prepared from pyruvic acid (L. Light and Co.) by the method of Robertson (1942). A sample of $\alpha$-ketoglutaric acid was kindly provided by Mr B. Slater and a sample of $\beta$-sulphonyl lactic acid by Dr P. Aichenegg.

Measurement of response of parathiotrophic mutants. The qualitative response of the parathiotrophic mutants was tested auxanographically on the basal medium solidified with $2 \%$ agar. The quantitative response of the mutants was estimated by a spore germination method (Shepherd, unpublished) and by measurement of growth rates on agar supplemented with the compounds under test. 


\section{RESULTS}

Preliminary experiments indicated that fresh mycelium showed very low and variable activities in synthesizing cysteine from sulphate, sulphite or thiosulphate. The activity of freeze-dried mycelium was very variable, while mycelium broken by ultrasonic disintegration, by shaking with glass beads (Mickle, 1948), by treating in the Hughes press (Hughes, 1951), or by grinding with powdered alumina (Mcllwain, Roper \& Hughes, 1948) showed negligible activities. Acetone powders of mycelium when prepared at a low temperature, showed a high activity which varied within the range of 38-82 $\mu \mathrm{g}$. cysteine produced/hr./100 mg. acetone powder with sulphite as the inorganic sulphur source, and $25-74 \mu \mathrm{g}$. cysteine produced $/ \mathrm{hr} . / 100 \mathrm{mg}$. acetone powder with thiosulphate as the inorganic sulphur source.

\section{Cysteine synthesis from sulphate and sulphite}

The mycelial acetone powders, when incubated alone in buffer, showed a small endogenous production of cysteine, possibly due to autolysis. As shown in Table 1, there was a considerable synthesis of cysteine when pyridoxal, glutamate and pyruvate were added to this system. The omission of glutamate, or pyruvate, caused only a $\mathbf{5 0} \%$ decrease of synthesis, as it was impossible to decrease significantly the amount of free internal amino acids in the mycelium by starvation. (After $6 \mathrm{hr}$. starvation approximately $80 \%$ of the original amount of glutamic acid still remained.) Other amino acids, such as alanine and aspartic acid, and $\alpha$-ketoglutaric acid and oxalacetic acid were less effective in the system. With sulphate as the inorganic sulphur source, the rate of synthesis was markedly lower, but the pattern followed was identical with that found with sulphite.

Table 1. Cysteine synthesis by Aspergillus nidulans in the presence of sulphate and sulphite

Acetone powder preparations of mycelium were incubated in a total volume of $10 \mathrm{ml}$. at $87^{\circ}$ for $5 \mathrm{hr}$. Cysteine and cystine were determined in the supernatant after incubation, the results being expressed as $\mu \mathrm{g}$. cysteine formed $/ \mathrm{hr} . / 100 \mathrm{mg}$. acetone powder. Four experiments recorded.

\begin{tabular}{|c|c|c|c|c|c|c|c|c|c|}
\hline & & Addi & ons & & & & & & \\
\hline & L-gluta- & & & & & & $\mathbf{E}$ & pt. & \\
\hline $\begin{array}{c}\text { Pyruvate } \\
(0 \cdot 1 \text { M) }\end{array}$ & $\begin{array}{c}\text { mate } \\
(0.1 \mathrm{M})\end{array}$ & $\begin{array}{c}\text { Pyridoxal } \\
(0.01 \mathrm{~m})\end{array}$ & $\begin{array}{c}\mathrm{SO}_{3} \\
(0.1 \mathrm{M})\end{array}$ & $\underset{(0.1 \mathrm{M})}{\mathrm{SO}_{4}}$ & $\begin{array}{c}\text { DL-Serine } \\
(0.1 \mathrm{~m})\end{array}$ & (1) & (2) & (3) & (4) \\
\hline- & - & - & - & - & - & 12 & 11 & 5 & 4 \\
\hline+ & + & + & + & - & - & 5 & 1 & 1 & $4(B)$ \\
\hline+ & + & + & - & - & - & 12 & 5 & 4 & 7 \\
\hline+ & + & + & + & - & - & 82 & 38 & 53 & 58 \\
\hline- & + & + & + & - & - & 44 & $\mathbf{3 4}$ & 23 & 34 \\
\hline+ & - & + & + & - & - & 42 & 32 & 38 & $\mathbf{3 4}$ \\
\hline- & - & + & + & - & - & 41 & 30 & - & - \\
\hline+ & + & - & + & - & - & 14 & 12 & 8 & 10 \\
\hline- & - & - & + & - & + & 9 & 7 & - & - \\
\hline+ & + & + & - & + & - & 34 & 21 & 23 & 30 \\
\hline
\end{tabular}

( $B$ signifies acetone powder suspended in buffer and heated for $10 \mathrm{~min}$, at $100^{\circ}$.) 


\section{Cysteine synthesis from thiosulphate}

There was a considerable synthesis of cysteine with the acetone powder, buffer and thiosulphate alone; this was markedly increased by the addition of serine. The rate of synthesis was not increased by the further addition of pyridoxal and a slight inhibition was noted upon the addition of other amino acids and keto acids (Table 2).

Table 2. Cysteine synthesis by Aspergillus nidulans in the presence of thiosulphate

Acetone powder preparations of mycelium were incubated in a total volume of $10 \mathrm{ml}$. at $37^{\circ}$ for $5 \mathrm{hr}$. Cysteine and cystine were determined in the supernatant after incubation, the results being expressed as $\mu \mathrm{g}$. cysteine formed $/ \mathrm{hr} . / 100 \mathrm{mg}$. acetone powder. Two experiments recorded.

\begin{tabular}{|c|c|c|c|c|c|c|}
\hline & & Additions & & & \multirow{2}{*}{\multicolumn{2}{|c|}{$\begin{array}{l}\text { Cysteine formed } \\
\text { Expt. }\end{array}$}} \\
\hline \multirow[b]{2}{*}{$\begin{array}{c}\text { Pyruvate } \\
(0 \cdot 1 \mathrm{M})\end{array}$} & \multirow{2}{*}{$\begin{array}{c}\text { L-Gluta- } \\
\text { mate } \\
(0 \cdot 1 \mathrm{M})\end{array}$} & \multirow[b]{2}{*}{$\begin{array}{c}\text { Pyridoxal } \\
(0 \cdot 01 \mathrm{M})\end{array}$} & \multirow[b]{2}{*}{$\begin{array}{c}\mathrm{S}_{2} \mathrm{O}_{3} \\
(0 \cdot 1 \mathrm{M})\end{array}$} & \multirow[b]{2}{*}{$\begin{array}{c}\text { DL-Serine } \\
(0 \cdot 1 \mathrm{M})\end{array}$} & & \\
\hline & & & & & (1) & (2) \\
\hline - & - & - & - & - & 11 & 5 \\
\hline - & - & - & + & - & 42 & 55 \\
\hline - & - & - & + & + & 68 & 74 \\
\hline+ & + & + & + & + & 48 & 51 \\
\hline - & - & + & + & - & 45 & 51 \\
\hline - & - & - & + & + & 9 & $7(\mathrm{~B})$ \\
\hline
\end{tabular}

(B signifles acetone powder suspended in buffer and heated for $10 \mathrm{~min}$. at $100^{\circ}$.)

\section{Cysteine sulphinic acid as an intermediate in the synthesis}

The production of cysteine sulphinic acid and the utilization of glutamic acid were demonstrated with sulphite as the inorganic sulphur source. With thiosulphate as the sulphur source, formation of cysteine sulphinic acid was not observed. The results obtained by a semi-quantitative estimation of changes in free internal amino acids, other than cysteine, are shown in Table 3.

\section{Table 3. Formation and utilization of amino acids during cysteine synthesis}

Acetone powder preparations of mycelium were incubated in a total volume of $10 \mathrm{ml}$. at $37^{\circ}$ for $5 \mathrm{hr}$. Amino acids were determined after incubation of hot water extracts of the acetone powders by the chromatographic method described in the text, the results being expressed in arbitrary units.

\begin{tabular}{|c|c|c|c|c|c|c|c|}
\hline \multicolumn{6}{|c|}{ Additions } & \multirow{2}{*}{\multicolumn{2}{|c|}{ Amino acids present }} \\
\hline & & & & & & & \\
\hline $\begin{array}{c}\text { Pyruvate } \\
(0 \cdot 1 \mathrm{M})\end{array}$ & $\begin{array}{c}\text { L-Giuta- } \\
\text { mate } \\
(0.1 \mathrm{M})\end{array}$ & $\begin{array}{c}\text { Pyridoxal } \\
(0 \cdot 01 \mathrm{M})\end{array}$ & $\begin{array}{c}\mathrm{SO}_{3} \\
(0.1 \mathrm{M})\end{array}$ & $\begin{array}{c}\mathrm{S}_{2} \mathrm{O}_{3} \\
(0 \cdot 1 \mathrm{M})\end{array}$ & $\begin{array}{c}\text { DL-Serine } \\
(0.1 \mathrm{M})\end{array}$ & $\begin{array}{l}\text { Cysteine } \\
\text { sulphinate }\end{array}$ & $\begin{array}{l}\text { Gluta- } \\
\text { mate }\end{array}$ \\
\hline- & - & - & - & - & - & 44 & 212 \\
\hline+ & + & + & + & - & - & 35 & 850 (B) \\
\hline $\begin{array}{l}T \\
+\end{array}$ & + & + & + & - & - & 112 & 713 \\
\hline- & + & + & + & - & - & 57 & 742 \\
\hline+ & - & + & + & - & - & 71 & 175 \\
\hline- & - & - & - & + & - & 30 & 225 \\
\hline+ & + & + & - & + & - & $\mathbf{3 0}$ & 818 \\
\hline- & - & - & - & + & + & 41 & 214 \\
\hline- & - & - & - & + & + & 41 & $112(B)$ \\
\hline
\end{tabular}

(B signifies acetone powder suspended in buffer and heated for $10 \mathrm{~min}$. at $100^{\circ}$.) 


\section{Growth studies with mutant organisms}

The results of growth studies with various mutants, by the colony diameter method, are shown in Table 4. Auxanographic tests gave results similar to those obtained by this method. In addition to the various mutants mentioned in the text, forty-two other mutants were obtained, the metabolic block in all cases being between sulphate and sulphite. Mutants 1 and 7 made relatively poor growth on all media, whereas the growth of the other mutants, where it occurred, was more like that of the wild type.

Table 4. Growth rates of parathiotrophic mutants on various sulphur sources

Figures express colony diameter in mm. after incubation at $37^{\circ}$ for $48 \mathrm{hr}$.

\begin{tabular}{|c|c|c|c|c|c|c|}
\hline \multirow[b]{2}{*}{$\begin{array}{l}\text { Sulphur compound } \\
(100 \mu \mathrm{g} . / \mathrm{ml} . \text { medium })\end{array}$} & \multicolumn{6}{|c|}{ Mutant nos. } \\
\hline & 2 & 8 & 9 & 1 & 7 & $\begin{array}{l}\text { Wild- } \\
\text { type }\end{array}$ \\
\hline Sulphate & 7 & $\mathbf{5}$ & 0 & $\mathbf{0}$ & 0 & 28 \\
\hline Sulphite & 18 & 14 & 0 & 0 & 4 & 28 \\
\hline Thiosulphate & $\mathbf{2 1}$ & 13 & 16 & 7 & 4 & 27 \\
\hline Cysteine sulphinic acid & 18 & 15 & $\mathbf{5}$ & 7 & 10 & 31 \\
\hline Cysteic acid & 24 & 14 & $\mathbf{0}$ & 10 & 10 & 29 \\
\hline Cysteine-S-sulphonic acid & 23 & 10 & 13 & 7 & 11 & 29 \\
\hline Taurine & 26 & 14 & $\mathbf{0}$ & 10 & 11 & 30 \\
\hline$\beta$-Sulphonyl lactic acid & $\mathbf{2 4}$ & 13 & $\mathbf{0}$ & 8 & 11 & 28 \\
\hline Formaldehyde sodium sulphoxylate & 23 & 15 & 0 & 2 & 10 & 34 \\
\hline$\beta$-Sulphonyl propionic acid & 20 & 16 & $\mathbf{0}$ & 10 & $\mathbf{9}$ & 31 \\
\hline$\alpha$-Dihydroxy- $\beta$-dithiolpropionic acid & 18 & 16 & 11 & 8 & 10 & 32 \\
\hline Cystine disulphoxide & 19 & 15 & 17 & 11 & 8 & 26 \\
\hline Formaldehyde bisulphite & 18 & 15 & 0 & 0 & 9 & 29 \\
\hline Isethionic acid & $\mathbf{2 4}$ & 15 & $\mathbf{0}$ & $\mathbf{0}$ & 11 & 18 \\
\hline Cysteine & 29 & 16 & 21 & 10 & 12 & 29 \\
\hline
\end{tabular}

Studies with mutant no. 7

Mutant no. 7 was studied in greatest detail because of the interest aroused by its poor growth on thiosulphate. The results of the metabolic experiments indicate that sulphite and thiosulphate may be metabolized by different paths, and it might be expected that mutants would be found which could utilize sulphite but not thiosulphate, and vice versa. That mutant no. 7 does not utilize either sulphite or thiosulphate to any large extent may indicate that these compounds are on the same pathway, or that some type of double block in two separate pathways is present. The response of this mutant to cysteine is shown in Fig. 1, and the quantitative response to various other sulphur compounds is shown in Fig. 2, as measured in spore germination tests.

\section{Apparent 'leakiness' of the mutants}

Table 5 illustrates ' leakiness', i.e. some growth and germination on sulphate, but much less than that of the wild type. Such 'leakiness' may be due to a slight ability of the mutant to convert sulphate to cysteine. Many of the 'leaky' mutants gave a negative auxanographic test for growth on sulphate, while showing some response in the spore germination tests. 


\section{Table 5. Incompleteness of the blocked reaction in the mutants}

Growth ability was tested by measurement of colony diameter after growth on a minimal medium with $100 \mu \mathrm{g} . / \mathrm{ml}$. sulphate as the sulphur source for $88 \mathrm{hr}$, at $37^{\circ}$, and by estimating spore germination in a sulphate-containing liquid medium.

$\begin{array}{ccc}\begin{array}{c}\text { Mutant } \\ \text { no. }\end{array} & \begin{array}{c}\text { Colony } \\ \text { diam. } \\ (\mathrm{mm} .)\end{array} & \begin{array}{c}\text { Degree of } \\ \text { germination }\end{array} \\ 1 & 0 & (\%) \\ 2 & 17 & 0 \cdot 4 \\ 3 & 18 & 6 \cdot 2 \\ 6 & 22 & 4 \cdot 7 \\ 7 & 2 & 89 \cdot 1 \\ 8 & 5 & 5 \cdot 1 \\ \text { Wild-type } & 65 & 5 \cdot 6 \\ & & 98 \cdot 8\end{array}$

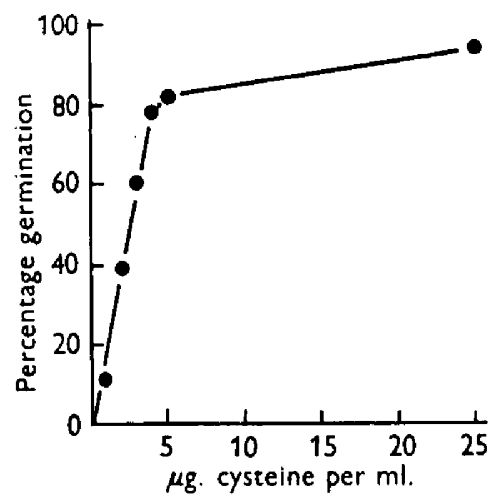

Fig. 1.

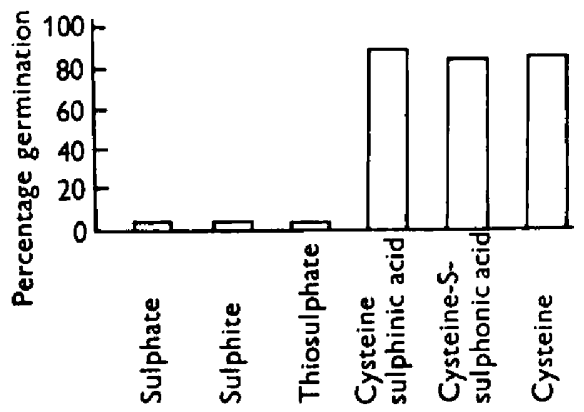

Fig. 2.

Fig. 1. Response of mutant no. 7 to cysteine. The percentage germination of conidia incubated in liquid medium containing cysteine was recorded after $6 \mathrm{hr}$. incubation at $87^{\circ}$.

Fig. 2. Response of mutant no. 7 to various sulphur sources. Sulphur compounds were added to liquid medium at a concentration of $100 \mu \mathrm{g} . / \mathrm{ml}$. and the percentage germination estimated after incubation at $37^{\circ}$ for $6 \mathrm{hr}$.

\section{DISCUSSION}

The evidence presented suggests that inorganic sulphur compounds may be synthesized biologically into cysteine via at least two different pathways in Aspergillus nidulans.

The pathway proposed by Kearney \& Singer (1952) for the metabolism of cysteine sulphinic acid in Proteus vulgaris and shown to be reversible in rabbit kidney by Chapeville \& Fromageot (1954) suggests the pathway starting with sulphate shown in Fig. 3. The latter part of this pathway is taken from the suggestion of Medes \& Floyd (1942) that cysteine is oxidized via cysteine sulphenic acid to cysteine sulphinic acid. This would explain the experimental data obtained with the wild-type Aspergillus nidulans preparations which use sulphate and sulphite as the inorganic sulphur sources, and also the growth 
behaviour of mutants $1,2,8,4,6,8$ and 9 . This pathway, however, provides no explanation for the metabolism of thiosulphate.

The stimulation of cysteine synthesis by serine, when thiosulphate is the inorganic sulphur source, and the complete lack of any stimulating effect of glutamic acid, keto acids or pyridoxal on this system, together with the evidence that there is no intermediate production of cysteine sulphinic acid,

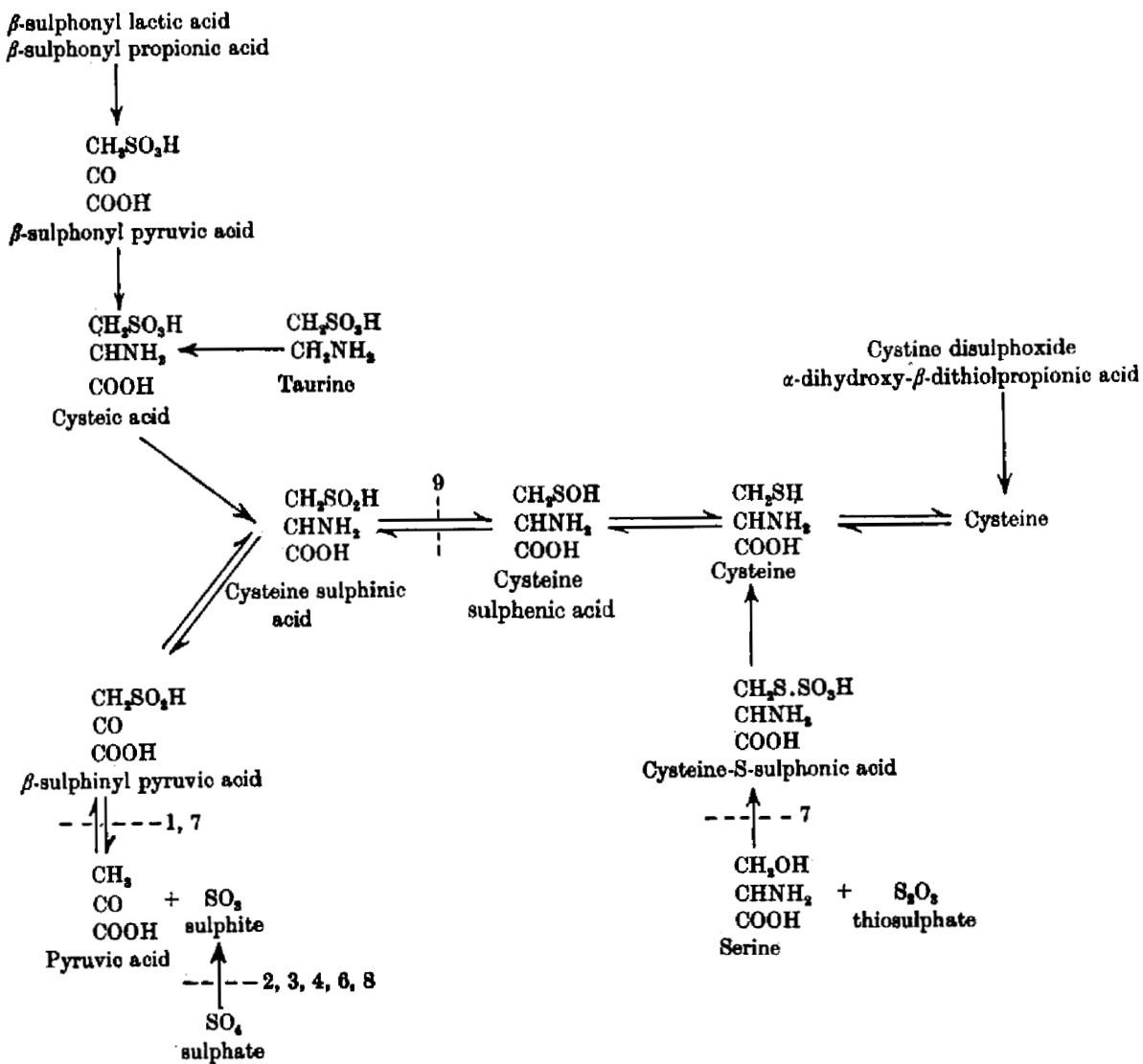

Fig. 3. Scheme for cysteine synthesis in Aspergillus nidulans. The positions of the postulated metabolic blocks in the various mutants is shown.

leads to the conclusion that thiosulphate is metabolized by an alternative pathway. The suggestion by Hockenhull (1949) that thiosulphate and serine combine to give cysteine-S-sulphonic acid, which gives rise to cysteine, would provide an alternative pathway for the metabolism of thiosulphate which would agree with the experimental data.

The pathway in mutant no. 7 is not entirely clear, but a block in the production of some unknown cofactor or energy-providing system common to both pathways, or a permeability change in the mycelium, are possible explanations of the behaviour of this mutant, which is apparently blocked in both metabolic pathways simultaneously. 
The experimental data for mutants nos. 1, 6 and 9 do not eliminate the possibility that sulphoxylic acid is an intermediate between sulphite and $\beta$-sulphinyl pyruvic acid, but the fact that the mutants 'delta', 'eta' and 'lambda' described by Hockenhull (1949) grew on sulphite and cysteine sulphinic acid, but not on sulphoxylate, precludes this hypothesis.

The evidence for the intermediacy of cysteine sulphinic acid in sulphate and sulphite metabolism, but not in thiosulphate metabolism, does not support the scheme proposed by Hockenhull (1949), but the proposed scheme in Fig. 3 is entirely compatible with his experimental results. Thus the mutants 'gamma, delta, eta, iota, lambda, sigma and upsilon' of Hockenhull are comparable with mutant no. 6, the mutant ' $\mathrm{mu}$ ' is equivalent to mutant no. 1 and mutants 'alpha, beta, epsilon, zeta, theta, kappa, xi, nu and omicron' are comparable with mutant no. 9.

The growth behaviour of mutants 1, 6 and 9 indicates that cysteic acid and taurine enter the system in the position proposed by Kearney \& Singer (1952), and it is presumed on further evidence from these mutants and from chemical considerations, that $\beta$-sulphonyl lactic and $\beta$-sulphonyl propionic acids enter the system through cysteic acid. It might be postulated that isethionic acid enters the system by amination to taurine, but the evidence from the mutants indicates that this compound enters the system at the level of sulphite.

Hockenhull produced evidence that several genes are required for the reduction step sulphate $\rightarrow$ sulphite, which implies that this apparently simple reduction may be complex, there being an unknown number of possible intermediates between sulphate and sulphite. If it be assumed that sulphoxylate enters the system after sulphate but before sulphite, possibly by giving rise to one of the postulated intermediates, the results of the growth of the various mutants on sulphoxylate may be explained. Alternatively, the equivalence of sodium formaldehyde sulphoxylate and free sulphoxylic acid may be questioned.

While the metabolic pathways outlined in Fig. 8 adequately explain the experimental data obtained with Aspergillus nidulans and with Escherichia coli, lack of sufficient evidence does not warrant the extension of this hypothesis to the results obtained with other organisms.

I wish to thank Mr W. S. L. Roberts for technical assistance with the spore germination experiments and Dr E. F. Gale, F.R.S., for his continued interest in this work.

\section{REFERENCES}

Chapeville, F. \& Fromageot, P. (1954). La formation enzymatique de l'acide cysteinesulphinique a partir de sulfte. Biochim. biophys. Acta, 14, 415 .

Clarke, H. J. (1932). The action of sulphite upon cysteine. J. biol. Chem. 97, 235.

Cowie, D. B., Bolton, E. T. \& SANDs, M. K. (1950). Sulphur metabolism in Escherichia coli. I. Sulphate metabolism of normal and mutant cells. J. Bact. 60, 233.

Fildes, P. \& Richardson, G. M. (1937). The nutrition of Staphylococcus aureus: sulphur requirements. Brit. J. exp. Path. 18, 292.

Fries, N. (1945). X-ray induced mutations in the physiology of Ophiostoma. Nature, Lond. 155, 757. 
Fromageot, C., Wookey, E. \& Charx, P. (1940). Sur la dégradation anaerobie de la cysteine par la desulphurase du foie. Enzymologia, 28, 198.

Hockenrule, D. J. D. (1948). Studies in penicillin production by Penicillium notatum in surface culture: II. Further studies in the metabolism of sulphur. Biochem. J. 43, 498.

Hockenhule, D. J. D. (1949). The sulphur metabolism of mould fungi: the use of 'biochemical mutant' strains of Aspergillus nidulans in elucidating the biosynthesis of cystine. Biochim. biophys. Acta, 3, $\mathbf{8 2 6}$.

Hugres, D. E. (1951). A press for disrupting bacteria and other microorganisms. Brit. J. exp. Path. 32, 97.

Kassell, B. \& Brand, E. (1938). The photometric determination of cystine, cysteine, ascorbic acid and related compounds with phosphotungstic acid. J. biol. Chem. 125, 115.

Kearney, E. B. \& Singer, T. P. (1952). Intermediary metabolism of cysteine sulphinic acid in cell-free extracts of Proteus vulgaris. Biochim. biophys. Acta, 8, 698.

Kearney, E. B. \& Singer, T. P. (1953). The oxidation of cysteine sulphinic and cysteic acids in Proteus vulgaris. Biochim. biophys. Acta, 11, 270.

Kharasch, M. S. \& Brown, H. C. (1940). Chlorinations with sulfuryl chloride. III. (a) The peroxide catalysed chlorination of aliphatic acids and acid chlorides. (b) The photochemical sulphonation of aliphatic acids. J. Amer. chem. Soc. 62, 925.

Lampen, J. O., Roepke, R. R. \& Jones, M. J. (1947). Studies on the sulphur metabolism of Escherichia coli. III. Mutant strains of Escherichia coli unable to utilize sulphate for their complete sulphur requirements, Arch. Biochem. 13, 55.

Levine, T, F. (1936). The oxidation of cystine in non-aqueous media. VI. A study of the reactions of the disulphoxide of L-cystine, especially of its dismutative decompositions. J. biol. Chem. 113, 571.

McIlwain, H., Roper, J. A. \& Hughes, D. E. (1948). Relationships in streptococei between growth and metabolism of glutamine. Biochem. J. 42, 402 .

Medes, G. \& Floyd, N. (1942). Metabolism of sulphur. II. Further investigations of the enzymic oxidation of sulphur-containing amino acids. Biochem. J. 36, 259.

Mickie, H. (1948). Tissue disintegrator. J. R. micr. Soc. 68, 10.

Phinney, B. O. (1948). Abstract in Genetics, 33, 624.

Phinney, B. O., Fling, M., Sheng, T. C. \& Honowitz, N. H. (1950). Unpublished experiments quoted in 'Biochemical genetics of Neurospora' by Horowitz, N.H. Advanc. Genet. 3, 33.

Ponteconvo, G. (1949). Auxanographic techniques in biochemical genetics. J. gen. Microbiol. 3, 122.

Ponteconvo, G. (1958). The genetics of Aspergillus nidulans. Advanc. Genet. 5, 141.

Robertson, W. B. (1942). The preparation of sodium pyruvate. Science, 96, 93.

Shinohara, K. (1982). Oxidation of cystine by iodine in aqueous media. J. biol. Chem. 96, 285.

Singer, T. P. \& Kearney, E. B. (1954). Pathways of L-cysteine-sulphinate metabolism in animal tissues. Biochim. biophys. Acta, 14, 570 .

Steingerg, R. A. (1941). Sulphur and trace element nutrition of Aspergillus niger. J. agric. Res. 63, 109.

Volkonsky, M. (1933). Sur l'assimilation des sulfates per les Champignons: euthiotrophie et parathiotrophie. C.R. Acad. Sci., Paris, 197, 712.

Westerman, B. D. \& Rose, W. C. (1928). The availability of disulphide acids as supplementing agents in diets deficient in cystine, II. $\alpha$-hydroxy- $\beta$ dithiolpropionic acid. J. biol. Chem. 79, 413.

Wohl, A. \& Oesterlin, C. (1901). Überführung der Weinsäure in Oxalessigsäure durch Wasserabspaltung bei niederer Temperatur. Ber. dtsch. chem. Ges. 34, 1139.

(Received 3 October 1955) 